\title{
PABA screening test for exocrine pancreatic function in infants and children
}

\author{
M. SACHER, A. KOBSA, AND D. H. SHMERLING
}

From the University Department of Paediatrics, Zurich, Switzerland

SUMMARY P-Amino-benzoic acid (PABA) is split specifically by pancreatic chymotrypsin from the synthetic tripeptide N-benzoyl-L-tyrosyl-PABA. The urinary excretion of absorbed PABA serves as an index for exocrine pancreatic function. The peptide $(0.015 \mathrm{~g} / \mathrm{kg})$ was administered orally to 20 controls (aged between 5 months and 16 years), 6 patients with exocrine pancreatic insufficiency caused by cystic fibrosis (CF), and 9 newborn infants. In the controls the mean 6-hour PABA recovery was $58 \cdot 5 \%( \pm 11 \cdot 2 \mathrm{SD})$. Recovery in patients with $\mathrm{CF}$ was lower $(\mathrm{P}<0.001)$ with no overlap. In newborn infants the mean 6-hour PABA recovery was $23 \cdot 4( \pm 17 \cdot 7 \mathrm{SD})$; overlapping in 3 instances with the results in CF patients. This simple, noninvasive test thus appears promising and merits further investigation in younger infants, especially newborns.

Existing procedures for evaluating exocrine pancreatic function in infants and children are either invasive and complicated, or inaccurate. The Lundh test and the pancreozymin-secretin test (Hadorn et al., 1968) are reliable, but long and tedious, so that neither is commonly used in clinical routine practice. The gelatin test and the chymotrypsin assay for faeces are simple to perform, but do not always give accurate results. A new pancreatic function test tested in animals and in adult patients has given promising results (Imondi et al., 1972; Gyr et al., 1975, 1976; Arvanitakis and Greenberger, 1976). The test is based on the oral administration of the synthetic tripeptide N-benzoyl-L-tyrosyl-Paminobenzoic acid. P-Aminobenzoic acid (PABA) is specifically split from the N-benzoyl-L-tyrosyl peptide in the small bowel by pancreatic chymotrypsin. After absorption from the gut and conjugation in the liver, PABA is excreted in the urine, and the amount of PABA excreted during a certain time serves as an index for chymotrypsin activity and, thus indirectly, also for exocrine pancreatic function. We examined the applicability of this PABA test in healthy children, in normal newborn infants, and in children with pancreatic insufficiency.

\section{Methods}

Three groups of children were studied. None received drugs containing PABA-derivatives.

Controls. 20 children ( 8 girls and 12 boys) aged Received 23 December 1977 between 5 months and 16 years (mean 8.01 years) were tested. These children were in hospital for various disorders, other than gastrointestinal and renal, and were thriving normally.

Newborn infants. 9 healthy newborn infants $(4$ girls and 5 boys) aged between 4 and 21 days (mean $8 \cdot 2$ days) were tested. None had any evidence of digestive, absorptive, or renal disorder and each was gaining weight normally.

Patients with exocrine pancreatic insufficiency (PI). 6 children ( 3 girls and 3 boys) aged between 7 weeks and 15 years (mean 6.5 years) with documented PI caused by cystic fibrosis (CF) were studied. Administration of pancreatic enzymes in these patients was discontinued 5 days before the test.

The PABA test with analysis of faecal chymotrypsin activity was applied to 19 of these children (7 controls, 7 newborn infants, and 5 CF patients).

\section{Procedure}

PABA test. The peptide was administered together with a normal breakfast or morning bottle feed; older children were encouraged to drink abundantly to ensure sufficient diuresis. One urine sample was collected before the test from the first 15 subjects to check for possible interfering aromatic amines. As the values found were negligible throughout this procedure was then discontinued.

After ingestion of the peptide, urine was collected during 4 consecutive 2 -hour periods. The children 
were allowed to drink and eat as usual during the test period.

The amount of peptide given, based on the $1 \mathrm{~g}$ dose used for adults (Arvanitakis and Greenberger 1976; Gyr et al., 1976), was $0.015 \mathrm{~g} / \mathrm{kg}$ (1 $\mathrm{g}$ peptide corresponding to $0.32 \mathrm{~g}$ PABA) (kindly supplied by the Chemical Research Department, Hoffmann-La Roche Co., Basel, Switzerland.) Chemical analysis of the peptide is described by Gyr et al. (1976). The concentration of PABA in the urine was determined by the method of Bratton and Marshall for aromatic amines, modified by Smith et al. (1945). PABA recovery was expressed as a percentage of the amount ingested.

Faecal chymotrypsin activity. Stool samples were collected on the same day, immediately before or after the PABA test, and determined by the method of Haverback et al. (1963).

Student's $t$ tests were performed to compare the results in the different groups.

\section{Results}

Controls. PABA recovery increased steadily in the 4 consecutive 2-hour periods. The mean cumulative 8 -hour recovery $(68 \cdot 6 \% \pm 12 \cdot 3 \mathrm{SD})$ was higher $(\mathrm{P}<0.01)$ than the mean cumulative 6-hour recovery $(58 \cdot 5 \pm 11 \cdot 2 \%)$. The coefficient of variation was $48 \%$ after 2 hours, $41 \%$ after 4 hours, and $19 \%$ after 6 hours. After 6 hours the value remained practically constant (8 hours, $18 \%$ ). A 6-hour collection seems therefore to be sufficient. The lower limit of normal (-2 SD) for the 6-hour period was $36 \%$ of the ingested PABA dose (Fig. 1).

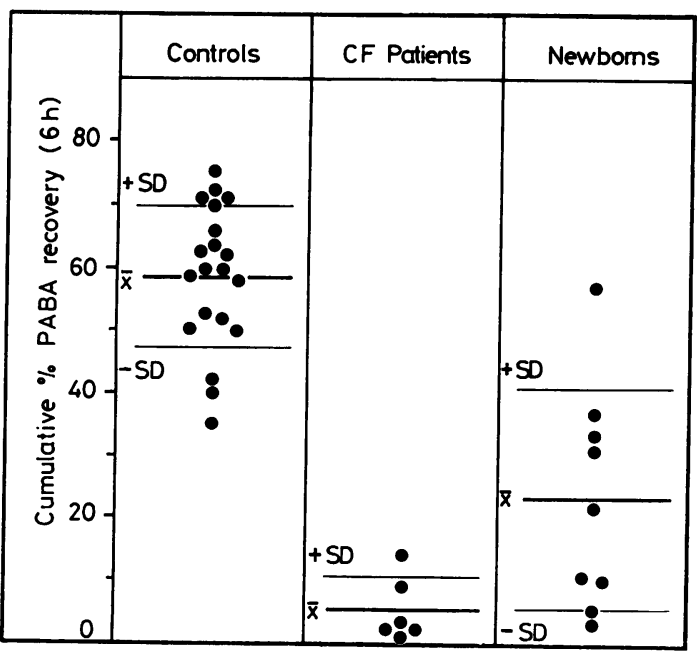

Fig. 1 6-hour $P A B A$ recovery in urine in three groups of infants and children.
CF Patients. The mean 6-hour $(5 \cdot 5 \pm 5 \cdot 3 \%)$ and the mean 8 -hour recovery $(7 \cdot 3 \pm 7 \cdot 5 \%)$ were both lower than that of the controls $(\mathrm{P}<0.001)$ with no overlap between the two groups (Fig. 1).

Newborn infants. The mean 6-hour recovery $(23.4 \pm$ $17.7 \%)$ and the mean 8 -hour recovery $(33.7 \pm$ $26.2 \%$ ) were both lower than that of the controls $(P<0.001)$. The coefficient of variation was $76 \%$ and $78 \%$ respectively for the 6-hour and the 8-hour recoveries. For 8 of the infants the 6-hour recovery and for 7 infants the 8-hour recovery was very much less than the lower limit (mean -2 SD) of normal in the controls. The 6-hour and the 8-hour recoveries overlapped in 4 instances and 3 instances respectively with those of the CF patients (Fig. 1).

Comparison with chymotrypsin excretion in the faeces. Fig. 2 shows the results of the PABA test and the chymotrypsin excretion for 19 subjects. 6 of the 7 controls subjected to analyses had normal chymotrypsin activities ( $>31 \mathrm{IU} / \mathrm{g}$ faeces). One subject had a low but not clearly pathological chymotrypsin activity (15.6 IU/g faeces) but a normal $(72 \%)$ PABA recovery. All CF patients had an abnormally low chymotrypsin activity ( $<6 \mathrm{IU} / \mathrm{g}$ faeces). In 4 newborn infants the chymotrypsin activity was normal ( $>31 \mathrm{IU} / \mathrm{g}$ faeces). The remaining 3 infants gave lower values (6-30 IU/g faeces), but none was

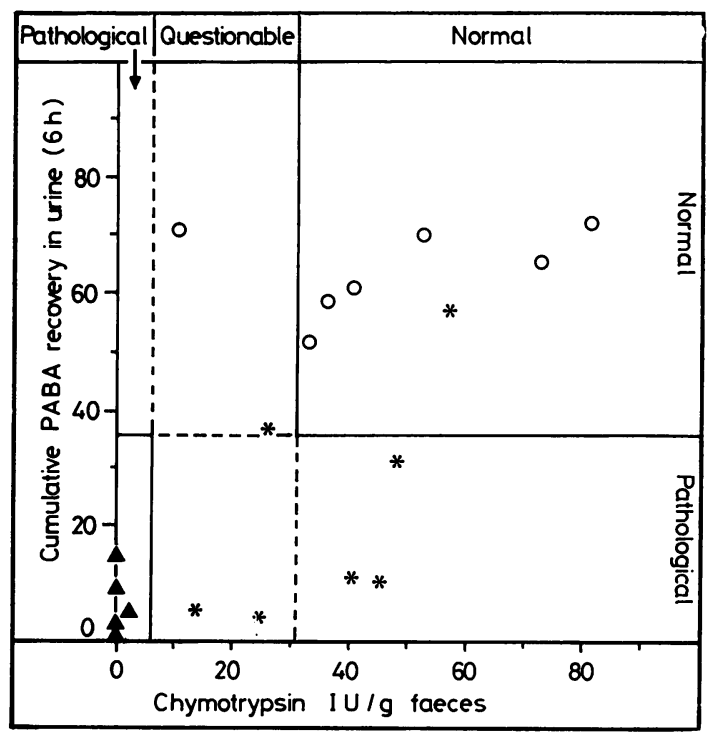

$\triangle$ CF patients; * newborn infants; $O$ controls.

Fig. 2 6-hour $P A B A$ recovery and chymotrypsin activity in faeces in three groups of infants and children. 
below $6 \mathrm{IU} / \mathrm{g}$, the lower limit of normal in our laboratory.

\section{Discussion}

The results of this preliminary study show that the PABA test is useful in the diagnosis of severe pancreatic insufficiency in children over 5 months. The PABA recovery in children with pancreatic insufficiency in CF differs greatly from that of the controls, with no overlap. The faecal chymotrypsin activity was consistently abnormal in CF patients, and (with one exception) normal in the controls. These results correspond with the observations made in adult patients with severe pancreatic insufficiency (Arvanitakis and Greenberger, 1976; Gyr et al., 1976). In the latter the PABA recovery correlated well with the results of secretin cholecystoinin-pancreozymin tests and the Lundh test (Gyr et al., 1976).

The results in the group of healthy newborn infants differed significantly from the controls. The mean PABA recovery was lower than in controls, but the variation was large. 4 infants showed low 6-hour recoveries in the range of the CF patients; two of them had in addition relatively low faecal chymotrypsin activities (13.8 and $24 \cdot 6 \mathrm{IU} / \mathrm{g}$ faeces). Similar low values are however quite common in this age group (unpublished data). The reason why the results of the PABA test in newborn infants differ from those in older controls is not clear; PABA excretion may be delayed by the low glomerular filtration rate of the newborn infant. Extension of the urine collection period to 12 or 24 hours with simultaneous measurement of creatinine excretion could test this speculation. The dose of peptide given to an infant is so small $(40-60 \mathrm{mg})$ that any slight error-caused for example by spilling the test solution during feeding - could lead to large errors in results.

We did not consider it ethical to perform pancreatic function tests such as a Lundh test or a pancreozymin-secretin test in the healthy controls and newborn infants solely to validate the PABA test. In none of these cases was there any evidence of malabsorption. The chymotrypsin values in almost all of the control patients, and the somewhat lower values in the newborn infants confirm that the PABA test gave no 'false normal' results.

The PABA test performed as described (one 6hour urine collection, normal feeding throughout the period of urine collection) proved to be simple and suitable for an outpatient procedure. The simplifications introduced did not reduce its reliability. Comparison of our results in children with those in adults for the 6-hour recovery (Gyr et al., 1976) and for the 8-hour recovery (Arvanitakis and Greenberger, 1976) showed no significant difference.

Further studies are necessary especially in healthy newborn infants and young babies. Furthermore, larger groups of patients with varying degrees of pancreatic insufficiency, and longitudinal observations of individual patients during the course of their disease, should provide further information about the quantitative possibilities of this test.

We thank the physicians and nurses of the Schweizerische Pflegerinnenschule, Zurich, for their care of newborn infants, Dr K. Gyr, Basel, and HoffmanLa Roche, Basel, for their help and for supplying PABA peptide, and Miss M. Görtz for secretarial work. M.S. was supported by research grants from the Roche-Studienstiftung, Basel, Switzerland.

\section{References}

Arvanitakis, C., and Greenberger, N. J. (1976). Diagnosis of pancreatic disease by a synthetic peptide. Lancet, 1, 663-666.

Gyr, K., Stalder, G. A., Schiffmann, I., Fehr, C., Wonderschmitt, D., and Fahrlaender, H. (1976). Oral administration of a chymotrypsin-labile-peptide-A new test of exocrine pancreatic function in man (PFT). Gut, 17, 27-32.

Gyr, K., Wolf, R. H., Imondi, A. R., and Felsenfeld, $\mathbf{O}$. (1975). Exocrine pancreatic function in protein deficient Patas monkeys studied by means of a test meal and an indirect pancreatic function test (PFT). Gastroenterology, 68, 488-494.

Hadorn, B., Zoppi, G., Shmerling, D. H., Prader, A., McIntyre, I., and Anderson, C. M. (1968). Quantitative assessment of exocrine pancreatic function in infants and children. Journal of Pediatrics, 73, 39-50.

Haverback, B. J., Dyce, B. J., Gutentag, Ph., and Montgomery, D. W. (1963). Measurement of trypsin and chymotrypsin in stool. A diagnostic test for pancreatic exocrine insufficiency. Gastroenterology, 44, 588-597.

Imondi, A. R., Stradley, R. P., and Wohlgemuth, R. L. (1972). Synthetic peptides in the diagnosis of exocrine pancreatic insufficiency in animals. Gut, 13, 726-731.

Smith, H. W., Finkelstein, N., Aliminosa, L., Crawford, B., and Graber, M. (1945). The renal clearances of substituted hippuric acid derivates and other aromatic acids in dog and man. Journal of Clinical Investigation, 24, 388-404.

Correspondence to $\mathrm{Dr}$ M. Sacher, Gottfried v. Preyer'sches Kinderspital, Schrankenberggasse 31, A-1100 Vienna, Austria. 